\title{
Effects of LEDs on Microhardness and Temperature Rise of Dental Composite Resins
}

\author{
Tae-Sung JEONG ${ }^{1}$, Young-Ran KIM ${ }^{1}$, Jong-Hwa KIM ${ }^{2}$, Hyung-Il KIM ${ }^{3}$ and Yong Hoon KWON ${ }^{3}$ \\ ${ }^{1}$ Department of Pediatric Dentistry, College of Dentistry, Pusan National University, Busan 602-739 Korea \\ ${ }^{2}$ Korea Basic Science Institute at Daegu branch, Kyungpook National University, Daegu 702-701, Korea \\ ${ }^{3}$ Department of Dental Materials, College of Dentistry, and Medical Research Institute, Pusan National University, Busan \\ 602-739 Korea \\ Corresponding author, Yong Hoon KWON; E-mail: y0k0916@pusan.ac.kr
}

Received April 5, 2007/Accepted June 25, 2007

\begin{abstract}
The purpose of this study was to examine the effects of LEDs on the polymerization of dental composite resins. Three composite resins and two LED units were used to evaluate the latter's effects on microhardness and temperature rise. In particular, two composite resins contained a coinitiator in addition to camphorquinone (CQ). The emission peak of the tested LEDs matched well with the absorption peak of CQ, while G-Light had one additional but weak peak near $410 \mathrm{~nm}$. As for the coinitiators, their absorption peaks were lower than $400 \mathrm{~nm}$. Within the specimens, incident photons from the LED units showed an exponential decrease in their counts as the specimens became thicker. However, microhardness values decreased and became almost linear at subsurface levels regardless of the curing unit. Among the composite resins, Z250 showed the highest microhardness value. As for the temperature rise $\left({ }^{\circ} \mathrm{C}\right)$ due to exothermic reaction at polymerization, it was higher than $5^{\circ} \mathrm{C}$ for the 40 -second light curing with both LED units. Among the specimens, Solitaire 2 cured with G-Light showed the highest temperature rise.
\end{abstract}

Keywords: LEDs, Composite resins, Microhardness

\section{INTRODUCTION}

Many commercially available dental composite resins which are initially soft and sticky pastes become hard after curing with blue light. When blue light is absorbed into a composite resin, it activates the photoinitiator, camphorquinone (CQ), and leads to the production of free radicals responsible for the initiation of the polymerization process. Conventional resin curing units, which emit light in a wavelength range of approximately $400-500 \mathrm{~nm}$, are based on the quartz-tungsten-halogen (QTH) lamp. As for $\mathrm{CQ}$ contained in the composite resins, it has a broad absorption band at approximately $400-500 \mathrm{~nm}$ with an absorption peak near $470 \mathrm{~nm}$.

To activate CQ, most QTH lights emit filtered light to match the $\mathrm{CQ}$ absorption band ${ }^{1-5)}$. On the other hand, recently available light emitting diodes (LEDs) focus on the CQ absorption peak ${ }^{6-9)}$. By emitting a relatively narrow-band light at approximately $430-480 \mathrm{~nm}$, it helps to efficiently maximize CQ activation. In terms of irradiation time, a duration of 40 seconds is sufficient to cure composite resins of $2 \mathrm{~mm}$ thickness with a light intensity of $400 \mathrm{mw} / \mathrm{cm}^{2,10)}$. As such, most commercially available curing units - be it based on QTH or LED - can be used in dental clinics.

To maximize resin polymerization, high concentration of $\mathrm{CQ}$ seems to be a logical option. However, high CQ concentration can cause problems in color matching. As such, CQ concentration is typically capped at a threshold of $1 \%(\mathrm{wt} \%)$. Recently, with a view to maximizing photoinitiation with lower $\mathrm{CQ}$ concentration, composite resins containing coinitiators - such as DMBZ (2,2-dimethoxy[1,2] diphenyletanone) and TPO (diphenyl (2,4,6trimethylbenzoyl)phosphinoxid) - in addition to CQ are commercially available $1^{1-13)}$. One key problem with these coinitiators lies in their absorption peaks - they are lower than $400 \mathrm{~nm}$. Since most light curing units based on the QTH lamp do not emit strong light lower than $400 \mathrm{~nm}$, a new light curing unit should be introduced for these composite resins. Indeed, recently available LEDs such as Ultra-Lume LED 5 (Ultradent Products, USA) and G-Light (GC Corp., Japan) are light curing units that can emit additional light near $400 \mathrm{~nm}$ while the main light remains near $460-470 \mathrm{~nm}$.

During light irradiation, composite resins produce heat as a result of the polymerization process. Such temperature rise in composite resins or dental restorative materials filled in the teeth during the light curing procedure has received much attention, because it can endanger oral tissue cells and dental pulp ${ }^{14,15)}$. It is noteworthy that most light curing units have light intensities approaching - if not exceeding $-1000 \mathrm{~mW} / \mathrm{cm}^{2}$ regardless of irradiation type. Therefore, heat generated in the composite resin during the polymerization process and heat from the light curing unit itself cannot be avoided - and should not be ignored.

The purpose of the present study was to examine the effects of LEDs on the polymerization of composite resins, by measuring the latter's microhardness 
and temperature rise. Two composite resins used in this study contained a coinitiator in addition to CQ.

\section{MATERIALS AND METHODS}

Composite resins and light curing units

Table 1 lists the characteristics of the three composite resins used in this study: Ceram X (CX), Solitaire 2 (S2), and Z250 (Z2). In particular, CX and S2 contained a coinitiator in addition to the standard photoinitiator, CQ. S2 and Z2 were hybrid resins, while CX contained nanofillers.

Two LED units, L.E. Demetron 1 (DE; Kerr, Dansbury, CT, USA) and G-Light (GL; GC Corp., Tokyo, Japan) were used in this study. Emission spectra of the tested LEDs were measured with a photodiode array detector (M1420, EG\&G PARC, Princeton, NJ, USA) connected to a spectrometer (SpectroPro-500, Acton Research, Acton, MA, USA). Output light intensity was adjusted using a filter to $1050 \mathrm{~mW} / \mathrm{cm}^{2}$ using a radiometer.

To prepare the specimens, resin was filled into a cylindrical acrylic ring mold (1, 2, and $3 \mathrm{~mm}$ in height with an inner diameter of $7 \mathrm{~mm}$ ) and light-cured for 40 seconds under a light intensity of $1050 \mathrm{~mW} / \mathrm{cm}^{2}$. The number of photons transmitted through specimens of different thicknesses was measured using the same photodiode detector and spectrometer. To this end, light-cure specimens of different thicknesses were placed over a stage with a hole of $6.8 \mathrm{~mm}$ diameter. Under this hole, the photodiode detector was placed in a fixed position for the measurement. Light was then irradiated with the light guide tip in contact with the top surface of the specimen.

\section{Absorbance measurement}

To measure the absorbance of the tested specimens, a Teflon disk (polytetrafluoroethylene, PTFE) was used. The baseline of a UV-VIS-NIR spectrophotometer (CARY 5G, Varian, Victoria, Australia) was calibrated by measuring the absorbance of the Teflon disk from 380 to $780 \mathrm{~nm}$. The Teflon disk was chosen as a sample holder because it could be used to coat the inside of the integrating sphere of the spectrophotometer.

Light-cured specimen was plugged into the hole at the center of the Teflon disk. The diameter and depth of the hole were $7.1 \mathrm{~mm}$ and $0.5 \mathrm{~mm}$ respectively. A hole of such dimensions would serve to ensure that the specimen was placed consistently at the center of the disk during measurement. Absorbance of the photoinitiator (CQ) and coinitiators (DMBZ and TPO) were measured using the same UV-VIS-NIR spectrophotometer after mixing CQ in 0.1\% methanol, or DMBZ (BASF, Ludwigshafen, Germany) and TPO (BASF, Ludwigshafen, Germany) in $0.1 \%$ ethanol.

\section{Microhardness measurement}

To measure the surface microhardness of the specimens $(n>5)$, resin was filled into a metal mold $(4 \times 2 \times 3 \mathrm{~mm})$ and light-cured for 20,40 , and $60 \mathrm{sec}-$ onds using the LED units. Diameter of the light guide tip was $8 \mathrm{~mm}$. After aging for 24 hours in a dark chamber, the microhardness values of the top $(\mathrm{z}=0)$, lateral $(\mathrm{z}=1$ and 2$)$, and bottom $(\mathrm{z}=3 \mathrm{~mm})$ surfaces were measured using a Vickers hardness tester (MVK-H1, Akashi Co., Tokyo, Japan) by making a microindentation ( $\mathrm{n}=12$ for each test condition). Each indentation was made under these conditions: 200-gf load for 10-second dwell time.

Table 1 Characteristics of the resins tested in this study

\begin{tabular}{|c|c|c|c|c|c|c|}
\hline & \multirow{2}{*}{ Composition } & \multirow{2}{*}{ Filler type } & \multicolumn{2}{|c|}{ Filler content ${ }^{\#}$} & \multirow{2}{*}{ Batch } & \multirow{2}{*}{ Company } \\
\hline & & & vol\% & wt\% & & \\
\hline $\mathrm{CX}$ & $\begin{array}{l}\text { Methacrylate modi- } \\
\text { fied polysiloxane, } \\
\text { Dimethacrylate, CQ, } \\
\text { TPO* }\end{array}$ & $\begin{array}{l}\text { Ba-Al-borosilicate glass, } \\
\text { Methacrylate function- } \\
\text { alised } \mathrm{SiO}_{2} \text { nano filler }\end{array}$ & 57 & $\begin{array}{l}\text { 76(glass \& nano } \\
\text { fillers), } 12 \\
\text { (nano ceramic } \\
\text { partilces) }\end{array}$ & $\begin{array}{l}04060 \\
02055\end{array}$ & Dentsply/Detrey \\
\hline $\mathrm{S} 2$ & $\begin{array}{l}\text { Bis-GMA, HPMA, } \\
\text { ETMA, PENTA, } \\
\text { CQ, DMBZ* }\end{array}$ & $\begin{array}{l}\text { Ba-Al-F glass, Ba glass, } \\
\text { porous } \mathrm{SiO}_{2}\end{array}$ & 58 & 75 & 050236 & Heraeus Kulzer \\
\hline $\mathrm{Z} 2$ & $\begin{array}{l}\text { Bis-GMA, TEGDMA, } \\
\text { UDMA, Bis-EMA, CQ }\end{array}$ & Zirconia, silica & 60 & 82 & $4 \mathrm{LNJ}$ & 3M ESPE \\
\hline
\end{tabular}

CX: Cream X, S2: Solitaire 2, Z 2: Z250

Bis-GMA: bisphenol A glycol dimethacyte; HPMA: 3-hydroxypropyl methacrylate; ETMA: ethyltriglycol trimethacrylate; PENTA: pentaerythrytol tetraacrylate; TEGDMA: triethylene glycol dimethacyte; UDMA: urethane dimethacyte; BisEMA: ethoxylated bisphenol A glycol dimethacyte; CQ: camphorquinone; TPO: Diphenyl (2,4,6-trimethylbenzoyl) phoshinoxid; DMBZ: 2,2-dimethoxy[1,2]diphenyletanone

\#: According to the manufacturers

*: According to Uhl et al. ${ }^{11}$ 


\section{Temperature measurement}

Temperature rise $\left({ }^{\circ} \mathrm{C}\right)$ in the specimens was measured by measuring the surface temperature of the resin specimens. Resin was filled into a cylindrical acrylic ring mold (height: $2 \mathrm{~mm}$; inner diameter: $7 \mathrm{~mm}$; outer diameter: $9 \mathrm{~mm}$ ), and the bottom of the ring mold was covered with a transparent glass slide (thickness: $200 \mu \mathrm{m}$ ). The soldered point of a thermocouple (T-type, OMEGA Engineering Inc., Stamford, CT, USA) was placed at the center of the top surface of the filled resin. At this point of time, the soldered point was applied with a small amount of thermally conducting paste (Omegatherm 201, OMEGA Engineering Inc., Stamford, CT, USA). This paste improved heat transfer and expanded the heat-path area from the surface to the thermocouple, thus increasing response speed and improving measurement accuracy.

The thermocouple was fixed on the top surface of the specimen. After which, the resin specimen was irradiated with the curing units from the bottom surface to the top surface for 40 seconds under a light intensity of $1050 \mathrm{~mW} / \mathrm{cm}^{2}$. The first temperature rise was then measured for 150 seconds. To ensure more complete curing, one additional light irradiation was performed for 60 seconds. After which, the second temperature measurement was performed during a third irradiation of 40 seconds with the same light intensity. Data were recorded using an $\mathrm{AD}$ conversion board and a PC at a sampling rate of $4 \mathrm{~Hz}$. Measurement was repeated five times by replacing the resin specimen every time. Minimum thermocouple resolution was $0.1^{\circ} \mathrm{C}$ and accuracy under $100^{\circ} \mathrm{C}$ was $0.6^{\circ} \mathrm{C}$.

\section{Statistical analysis}

Data acquired for temperature rise were analyzed by two-way ANOVA at 0.05 level of significance. Tukey's test was then followed by multiple comparison test if necessary.

\section{RESULTS}

Figure 1 shows the light emission spectra of the LED units used and the absorption spectra of the photoinitiators. DE had only one strong emission peak near $460 \mathrm{~nm}$, whereas GL showed one strong peak near $470 \mathrm{~nm}$ and another weak peak near 410 nm. CQ had a strong but broad absorption peak near $460 \mathrm{~nm}$, whereas DMBZ and TPO showed absorption peaks below $400 \mathrm{~nm}$. Table 2 shows the number of photons detected in specimens of different thicknesses for different LEDs. The attenuation coefficients $\left(\mathrm{AC}, \mathrm{mm}^{-1}\right)$ evaluated from the detected photons through an exponential fitting are also shown in Table 2. Within the same specimen, slightly different $\mathrm{AC}$ values were shown for different LEDs. The AC values ranged from -1.19 to -1.57 , depending on the resin specimen and curing LED. Figure 2 shows the absorbance spectra of the resin specimens of different thicknesses cured with different LEDs. Within the same resin specimen, different absorbance spectra were recorded for specimens cured

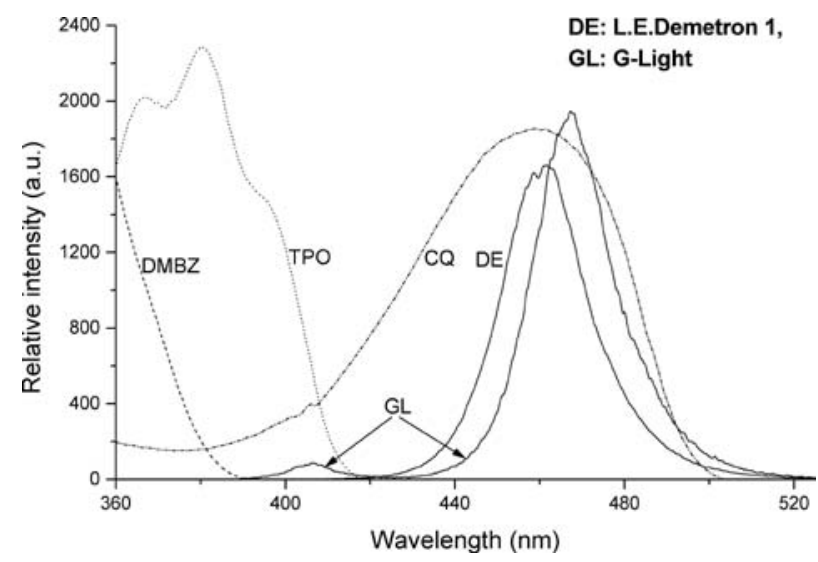

Fig. 1 Emission spectra of the LED units and the absorption spectra of the photoinitiators used in this study.

Table 2 Detected photon counts of the light curing units without and with resin specimens.

\begin{tabular}{|c|c|c|c|c|c|c|c|}
\hline \multicolumn{2}{|c|}{ Specimen thickness } & $\mathrm{DE}$ & $\mathrm{AC}$ & $\mathrm{R}^{2}$ & GL & $\mathrm{AC}$ & $\mathrm{R}^{2}$ \\
\hline \multirow{4}{*}{$\mathrm{CX}$} & no specimen & $13080 \pm 215$ & & & $13312 \pm 262$ & & \\
\hline & $1 \mathrm{~mm}$ & $2350 \pm 165$ & & & $2423 \pm 198$ & & \\
\hline & $2 \mathrm{~mm}$ & $730 \pm 115$ & -1.32 & 0.96 & $1105 \pm 162$ & -1.19 & 0.94 \\
\hline & $3 \mathrm{~mm}$ & $330 \pm 49$ & & & $478 \pm 53$ & & \\
\hline \multirow{3}{*}{$\mathrm{S} 2$} & $1 \mathrm{~mm}$ & $1701 \pm 152$ & & & $1763 \pm 180$ & & \\
\hline & $2 \mathrm{~mm}$ & $523 \pm 53$ & -1.57 & 0.98 & $649 \pm 87$ & -1.45 & 0.95 \\
\hline & $3 \mathrm{~mm}$ & $143 \pm 20$ & & & $230 \pm 31$ & & \\
\hline \multirow{3}{*}{$\mathrm{Z} 2$} & $1 \mathrm{~mm}$ & $1890 \pm 125$ & & & $2114 \pm 180$ & & \\
\hline & $2 \mathrm{~mm}$ & $682 \pm 59$ & -1.44 & 0.97 & $735 \pm 67$ & -1.31 & 0.94 \\
\hline & $3 \mathrm{~mm}$ & $218 \pm 25$ & & & $369 \pm 35$ & & \\
\hline
\end{tabular}

AC: Attenuation coefficient $\left(\mathrm{mm}^{-1}\right), \mathrm{R}^{2}$ : Correlation coefficient 
Table 3 Microhardness (Hv) change in specimens

\begin{tabular}{|c|c|c|c|c|c|c|c|}
\hline & \multirow{3}{*}{$\begin{array}{c}\text { Depth } \\
(\mathrm{mm})\end{array}$} & \multicolumn{6}{|c|}{ Curing time (sec) } \\
\hline & & \multicolumn{3}{|c|}{ (DE) } & \multicolumn{3}{|c|}{ (GL) } \\
\hline & & 20 & 40 & 60 & 20 & 40 & 60 \\
\hline \multirow{4}{*}{ CX } & 0 & $52.8 \pm 0.8$ & $55.9 \pm 1.3$ & $56.7 \pm 2.4$ & $54.8 \pm 1.8$ & $54.4 \pm 1.3$ & $56.4 \pm 1.4$ \\
\hline & 1 & $46.6 \pm 1.9$ & $51.4 \pm 1.1$ & $50.9 \pm 2.1$ & $46.7 \pm 1.4$ & $52.4 \pm 0.8$ & $53.7 \pm 1.7$ \\
\hline & 2 & $35.6 \pm 1.5$ & $49.2 \pm 1.1$ & $48.2 \pm 1.6$ & $38.3 \pm 1.5$ & $47.8 \pm 1.5$ & $51.5 \pm 2.0$ \\
\hline & 3 & $26.0 \pm 1.6$ & $47.1 \pm 1.2$ & $47.5 \pm 1.6$ & $33.5 \pm 2.5$ & $46.0 \pm 1.3$ & $50.4 \pm 1.9$ \\
\hline \multirow{4}{*}{$\mathrm{S} 2$} & 0 & $35.0 \pm 1.4$ & $40.2 \pm 1.6$ & $41.9 \pm 2.3$ & $37.0 \pm 1.0$ & $39.7 \pm 1.5$ & $40.9 \pm 2.1$ \\
\hline & 1 & $32.4 \pm 1.4$ & $38.8 \pm 0.9$ & $40.5 \pm 1.9$ & $34.4 \pm 1.6$ & $37.4 \pm 1.1$ & $37.6 \pm 1.6$ \\
\hline & 2 & $22.0 \pm 1.8$ & $33.3 \pm 2.0$ & $37.8 \pm 1.9$ & $22.0 \pm 2.0$ & $32.7 \pm 1.7$ & $31.8 \pm 2.0$ \\
\hline & 3 & $15.2 \pm 1.5$ & $28.5 \pm 1.5$ & $40.4 \pm 1.1$ & $16.8 \pm 0.8$ & $28.9 \pm 1.3$ & $38.6 \pm 1.7$ \\
\hline \multirow{4}{*}{$\mathrm{Z} 2$} & 0 & $80.1 \pm 1.7$ & $82.3 \pm 2.1$ & $83.8 \pm 2.2$ & $76.9 \pm 2.1$ & $82.7 \pm 1.3$ & $82.6 \pm 2.1$ \\
\hline & 1 & $72.4 \pm 1.6$ & $73.7 \pm 1.8$ & $79.3 \pm 3.1$ & $73.4 \pm 2.0$ & $77.7 \pm 2.3$ & $80.0 \pm 1.7$ \\
\hline & 2 & $64.5 \pm 2.3$ & $73.1 \pm 1.4$ & $77.8 \pm 2.1$ & $66.2 \pm 1.4$ & $74.5 \pm 2.1$ & $78.0 \pm 2.6$ \\
\hline & 3 & $60.5 \pm 1.4$ & $72.6 \pm 0.8$ & $77.2 \pm 1.3$ & $63.4 \pm 1.3$ & $73.3 \pm 1.4$ & $78.0 \pm 1.9$ \\
\hline
\end{tabular}

(a)

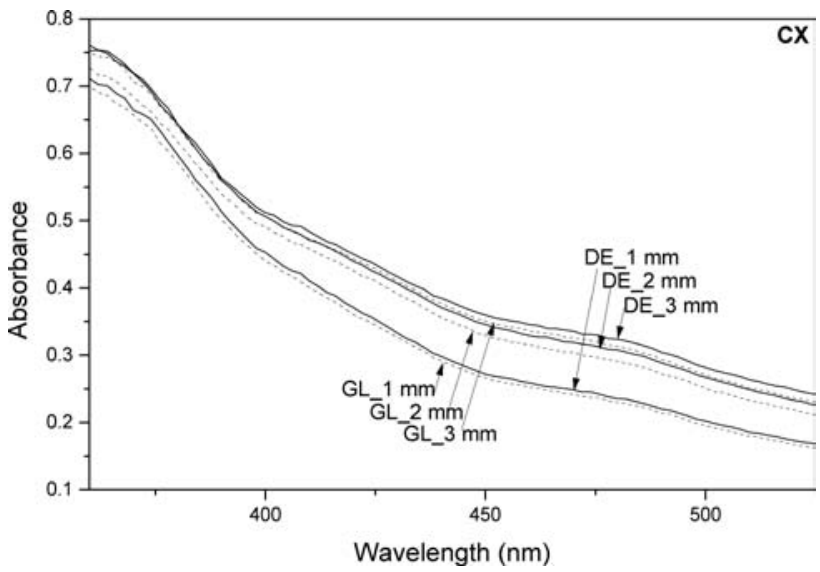

(b)

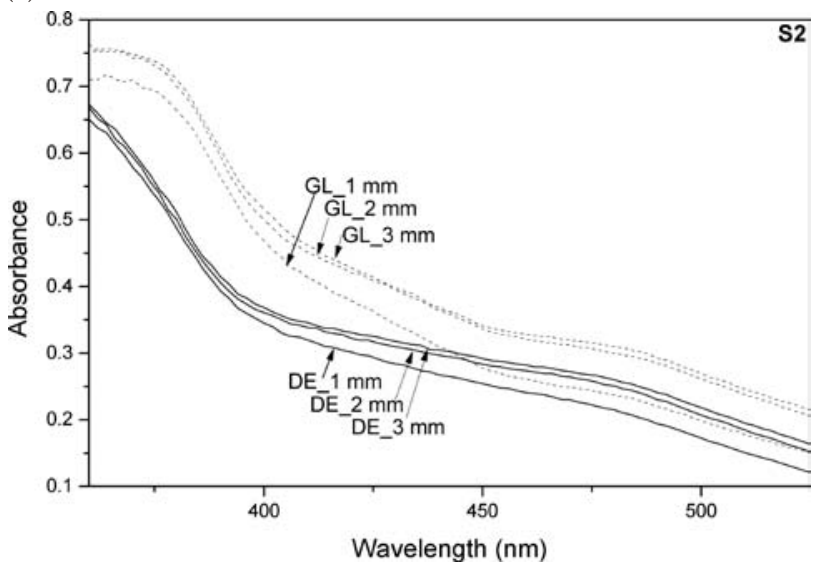

Fig. 2 Absorbance spectra of the resin specimens (CX (a), S2 (b), and Z2 (c)) of different thicknesses cured with different LEDs. Solid and dotted lines are for DE and GL respectively. (c)

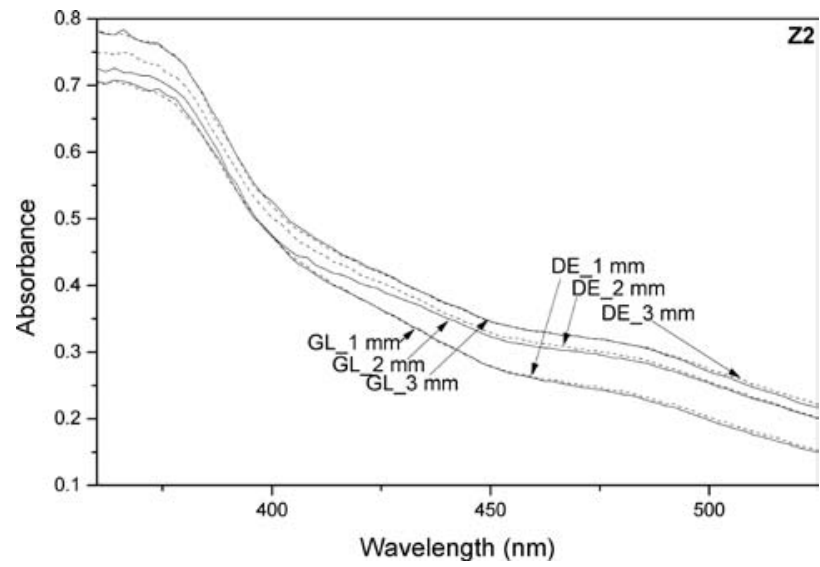

Table 4 Maximum temperature rise due to exothermic reaction $\left(\Delta \mathrm{T},{ }^{\circ} \mathrm{C}\right)$ in specimens during 40 -second irradiation by curing light

\begin{tabular}{lrrr}
\hline & \multicolumn{1}{c}{$\mathrm{DE}^{1}$} & \multicolumn{1}{c}{$\mathrm{GL}^{2}$} & $p$-values \\
\cline { 2 - 4 } $\mathrm{CX}^{\mathrm{A}}$ & $7.5 \pm 0.6$ & $6.5 \pm 0.5$ & \\
$\mathrm{~S} 2^{\mathrm{B}}$ & $11.8 \pm 0.7$ & $15.6 \pm 0.8$ & $\alpha<0.0001$ \\
$\mathrm{Z}^{\mathrm{C}}$ & $5.4 \pm 0.5$ & $6.7 \pm 0.6$ & $\beta=0.0002$ \\
\hline
\end{tabular}

*Statistically significant difference on resin product is shown by superscript letters ${ }^{\mathrm{A}, \mathrm{B}, \mathrm{C}}$, on light-curing unit by superscript number ${ }^{1,2}$. Same letters or numbers are not signficantly different $(\mathrm{p}<0.05)$.

*On $p$-values, the letters $\alpha$ and $\beta$ denote resin product and light-curing unit, respectively. 

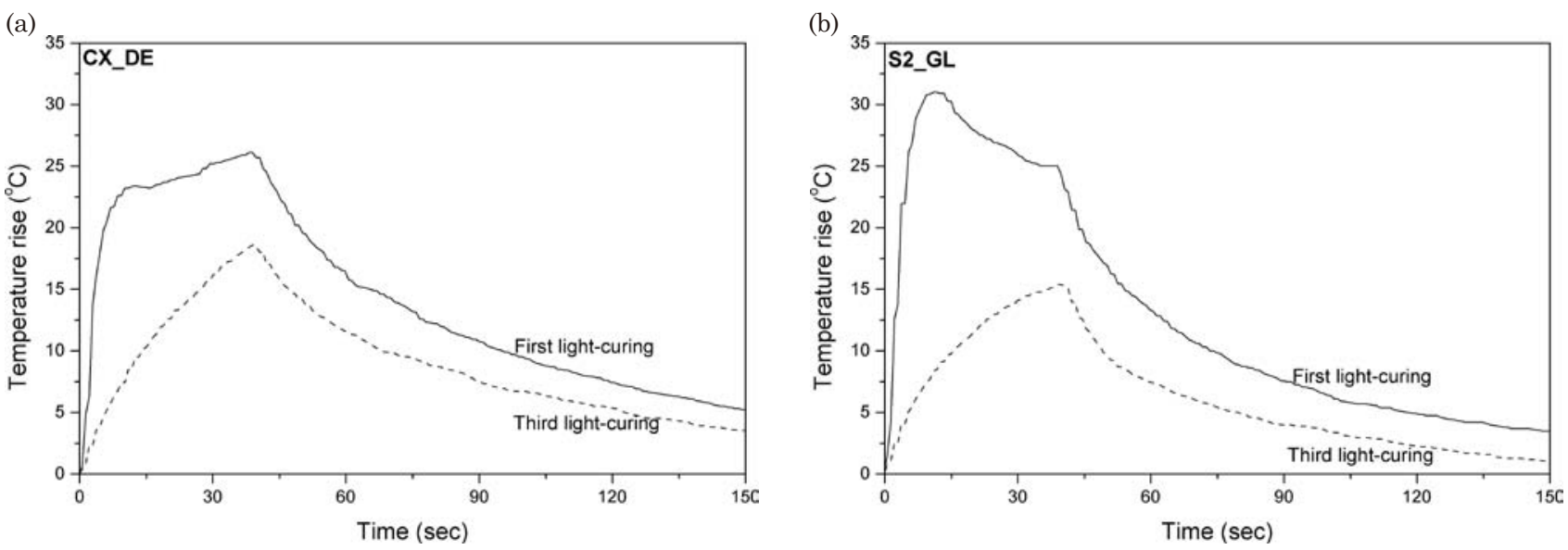

Fig. 3 Temperature distributions on the bottom surface of 2-mm thick specimens (curing unit: DE, specimen: CX (a); curing unit: GL, specimen: S2 (b)).

with different LEDs. Regardless of resin specimen and LED, higher absorbance was observed at lower wavelengths.

Table 3 shows the microhardness changes in specimens for different conditions (depth, composite resin, curing time, and curing LED). In the resin specimens, microhardness value gradually increased as curing time increased. Then, within the same resin specimen, microhardness changes with different curing units at any given depth were similar. However, in most cases, microhardness values decreased and became almost linear at subsurface levels - unlike the exponential decrease of photon counts. Z2 showed the highest microhardness values among the specimens. Then, between $\mathrm{CX}$ and S2 which had similar filler volume fractions, the former showed much higher microhardness values than the latter.

Figure 3 shows the temperature distributions on the bottom surface of 2-mm-thick specimens for first light curing (solid line) and third light curing (dotted line). The case of Z2 was not shown here. Nonetheless, with Z2, temperature distributions as those in Fig. 3 for both LEDs were observed. Table 4 shows the maximum temperature rise $\left(\Delta \mathrm{T},{ }^{\circ} \mathrm{C}\right)$ due to exothermic reaction in the specimens. Each value obtained was the difference between the peak values of the solid and dotted lines. Different curing units induced different temperature increases within the same resin specimen, and S2 showed a much higher temperature rise than $\mathrm{CX}$ and $\mathrm{Z} 2$ regardless of the curing LED. Table 4 also shows the statistically significant influences of resin product and LED on temperature rise. On the overall, all specimens showed a temperature rise greater than $5^{\circ} \mathrm{C}$ regardless of the curing LED.

\section{DISCUSSION}

The composite resins tested in this study (except Z2) contained a coinitiator such as DMBZ or TPO in addition to $\mathrm{CQ}$. Upon examining the absorbance spectra of these photoinitiators, only CQ showed a good match with the spectra of the LEDs tested. As for DMBZ and TPO, they had absorption peaks lower than $400 \mathrm{~nm}$. Therefore, activation of these coinitiators by light with a wavelength near $410 \mathrm{~nm}$ or longer would not seem effective.

In the case of $\mathrm{CQ}$, its yellow color becomes invisible after polymerization is completed ${ }^{16)}$. As for DMBZ and TPO, they were introduced only recently. Therefore, no reports are available about their color change due to polymerization and about their optimal concentration for maximum polymerization in conjunction with the $\mathrm{CQ}$ content. According to Figs. 2(a) and (b), the absorbance spectra did not show any apparent peak near and below $400 \mathrm{~nm}$ which might indicate the inclusion of coinitiator or the presence of any residual coinitiator. No appearance of any peak might be related to the low quantity of coinitiator within the specimens. However, it should also be clarified that since we did not know about the spectral patterns before and after light curing, further investigations may be needed. Apart from DMBZ and TPO, some other coinitiators were also tested recently ${ }^{17-19)}$. Amongst which, 1-phenyl-1,2propanedione (PPD) showed an efficient and synergistic photoinitiation reaction when combined with CQ. In the present study, the pure role of coinitiators pertaining to polymerization was not conducted. Therefore, their contribution to polymerization in a quantitative standard has not been clarified. Further experiments are hence needed to determine their contribution.

Between the LEDs tested, DE showed slightly higher $\mathrm{AC}$ values than $\mathrm{GL}(-1.32$ and -1.57 vs. 
-1.19 and -1.45). For the same resin product, fewer photons from DE reached the bottom surface of the specimens compared to GL (Table 2). Compared to the initial photons, the photons that reached the bottom surface of the specimens were reduced by 28-91 times, depending on the specimen tested.

Despite vast differences in photon count, this was not so for the resultant microhardness values even at curing times longer than 40 seconds. At the bottom surface, microhardness reduced by approximately $39-57 \%$ than that of the top surface after light curing for 20 seconds. In the case of CX, microhardness at the bottom surface was approximately $84-89 \%$ that of the top surface after 60 -second light curing. In the case of S2, microhardness values of the top and bottom surfaces were similar after 60second light curing, regardless of the curing unit. However, one unexpected result in S2 was the sudden increase of microhardness at the bottom surface as compared to the top surface. It was not clear why such a change occurred regardless of curing unit. Therefore, this is also one aspect that needs further investigation. Apart from this exceptional case, microhardness generally decreased linearly as the specimens became thicker despite an exponential decrease in the number of photons at subsurface levels.

CX and S2 had similar filler volume fractions: $57 \mathrm{vol} \%$ for CS and $58 \mathrm{vol} \%$ for S2. Thus, it was not clear why CX had higher microhardness values than S2. One possible reason could be the difference in monomer composition and filler content. To date, the effect of nanofillers on microhardness remains unclear. However, in general, dental nanocomposite resins have excellent optical properties, high flexural strength, and low polymerization shrinkage ${ }^{20,21)}$. From the similar microhardness values regardless of light curing unit, two possible conclusions could be drawn: (1) The contained coinitiators were not active in enhancing polymerization because their absorption peaks were located outside the emission peaks of the tested LEDs; (2) Since DE and GL yielded similar microhardness values, the additional emission peak of GL near $410 \mathrm{~nm}$ was not effective in activating photoinitiators.

Temperature rise in the specimens at first light curing was attributed to two sources: heat generated by exothermic reaction during polymerization and by the light curing unit itself. To obtain a pure temperature rise by polymerization, it is necessary to eliminate the temperature rise caused by the light curing unit. To achieve a more complete polymerization, one additional light irradiation was performed on the pre-cured specimens. A second temperature rise measurement was then performed during the third light irradiation. Temperature rise in this case was solely due to the light curing unit itself. It is noteworthy that when photons were guided through the fiber optic, some photons were absorbed into the fiber optic. As a result, absorbed photon energy was transformed into heat and made the light guide tip hot. Difference of the first and second temperature readings thus reflected pure temperature rise during the polymerization process. With this calculation method, the estimated pure temperature rise in the specimens was greater than $5{ }^{\circ} \mathrm{C}\left(6.5-15.6{ }^{\circ} \mathrm{C}\right.$ according to test conditions).

During the first and third light curing sessions, the maximum temperature readings in the specimens were approximately $47-54^{\circ} \mathrm{C}$ and $38-45^{\circ} \mathrm{C}$ respectively, depending on the resin product and light curing unit. In this study, measurement of the temperature rise was performed in an open environment whereby the initial temperature was $23{ }^{\circ} \mathrm{C}$. In complicated oral situations, the real temperature rise might be different. The heat sink effect created by circulating blood could modulate increasing temperatures. On the other hand, a closed oral cavity might further enhance or prolong temperature rise during light irradiation. Since high temperatures result in a rapid breakdown of pulpal microcirculation, cooling caused by circulating blood might thus be weakened ${ }^{22-24)}$. At this juncture, it must be highlighted that temperature rise affects cellular metabolism and function. On this note, a temperature rise over $5{ }^{\circ} \mathrm{C}$ caused by any type of external heat source could cause dental pulp to overheat and necrose. Therefore, temperature rise within the pulp cavity should be maintained below $5{ }^{\circ} \mathrm{C}$ through proper cooling with water or air ${ }^{14,15)}$.

In conclusion, the two LEDs tested yielded similar microhardness values within the same resin product despite their spectral differences. For the specimens tested, the maximum temperatures attained with the two LEDs $\left(47-54^{\circ} \mathrm{C}\right.$ and $\left.38-45^{\circ} \mathrm{C}\right)$ were much higher than the normal body temperature - and such high temperatures are detrimental to the dental pulp. As for the coinitiators in the polymerization process, they did not seem to exhibit any synergistic effect because their absorption peaks were located outside the emission peaks of the tested LEDs. Nonetheless, for a more detailed understanding on the interactions of coinitiators with LEDs and CQ, further investigations are strongly encouraged.

\section{REFERENCES}

1) Rueggeberg FA, Ergle JW, Mettenburg DJ. Polymerization depths of contemporary light-curing units using microhardness. J Esthet Dent 2000; 12: 340349.

2) Price RB, Derand T, Loney RW, Andreou P. Effect of light source and specimen thickness on the surface hardness of resin composite. Am J Dent 2002; 15: 47-53. 
3) Hofmann N, Hugo B, Klaiber B. Effect of irradiation type (LED or QTH) on photo-activated composite shrinkage strain kinetics, temperature rise, and hardness. Eur J Oral Sci 2002; 110: 471-479.

4) Asmussen E, Peutzfeldt A. Temperature rise induced by some light emitting diode and quartz-tungstenhalogen curing units. Eur J Oral Sci 2005; 113: 9698.

5) Bouillaguet S, Caillot G, Forchelet J, Cattani-Lorente M, Wataha JC, Krejci I. Thermal risks from LEDand high-intensity QTH-curing units during polymerization of dental resins. J Biomed Mater Res 2005; 72B: 260-267.

6) Ozturk B, Ozturk AN, Usumez A, Usumez S, Ozer F. Temperature rise during adhesive and resin composite polymerization with various light curing sources. Oper Dent 2004; 29: 325-332.

7) Knezevic A, Tarle Z, Meniga A, Sutalo J, Pichler G. Influence of light intensity from different curing units upon composite temperature rise. J Oral Rehabil 2005; 32: 362-367.

8) Lohbauer U, Rahiotis C, Kramer N, Petschelt A, Eliades G. The effect of different light-curing units on fatigue behavior and degree of conversion of a resin composite. Dent Mater 2005; 21: 608-615.

9) Oberholzer TG, Du Preez IC, Kidd M. Effect of LED curing on the microleakage, shear bond strength and surface hardness of a resin based composite restoration. Biomaterials 2005; 26: 3981-3986.

10) Rueggeberg FA, Caughman WF, Curtis JW. Effect of light intensity and exposure duration on cure of resin composite. Oper Dent 1994; 19: 26-32.

11) Uhl A, Mills RW, Vowles RW, Jandt KD. Knoop hardness depth profiles and compressive strength of selected dental composites polymerized with halogen and LED light curing technologies. J Biomed Mater Res 2002; 63B: 729-738.

12) Uhl A, Mills RW, Jandt KD. Photoinitiator dependent composite depth of cure and knoop hardness with halogen and LED light curing units. Biomaterials 2003; 24: 1787-1795.

13) Uhl A, Sigusch BW, Jandt KD. Second generation LEDs for the polymerization of oral biomaterials.
Dent Mater 2004; 20: 80-87.

14) Zach L, Cohen G. Pulpal response to externally applied heat. Oral Surf Oral Med Oral Pathol 1965; 19: 515-530.

15) Hussey DL, Biagioni PA, Lamey PJ. Thermographic measurement of temperature change during resin composite polymerization in vitro. J Dent 1995; 23: 267-271.

16) Taira M, Urabe H, Hirose T, Wakasa K, Yamaki M. Analysis of photo-initiators in visible-light-cured dental composite resins. J Dent Res 1988; 67: 24-28.

17) Sun GJ, Chae KH. Properties of 2,3-butanedione and 1-phenyl-1,2-prppanedione as new photosensitizers for visible light cured dental resin composites. Polymer 2000; 41: 6205-6212.

18) Davidenko N, Garcia O, Sastre R. The efficiency of titanocene as photoinitiator in the polymerization of dental formulations. J Biomater Sci Polymer Edn 2003; 14: 733-746.

19) Emami N, Soderholm KJ. Influence of light-curing procedures and photo-initiator/co-initiator composition on the degree of conversion of light-curing resins. J Mater Sci Mater Med 2005; 16: 47-52.

20) Lee YK, Lim BS, Rhee SH, Yang HC, Powers JM. Changes of optical properties of dental nano-filled resin composites after curing and thermocycling. J Biomed Mater Res 2004; 71B: 16-21.

21) Lohbauer U, Frankenberger R, Kramer N, Petschelt A. Strength and fatigue performance versus filler fraction of different types of direct dental restoratives. J Biomed Mater Res 2006; 76B: 114-120.

22) Raab WH. Temperature related changes in pulpal microcirculation. Proc Finn Dent Soc 1992; 81: 469479.

23) Noda M, Wataha JC, Kaga M, Lockwood PE, Volkmann KR, Sano H. Components of dentinal adhesives modulate heat shock protein 72 expression in heat-stressed THP-1 human monocytes at sublethal concentrations. J Dent Res 2002; 81: 265-269.

24) Wataha JC, Lewis JB, Lockwood PE, Hsu S, Messer RL, Rueggeberg FA, Bouillaguet S. Blue light differentially modulates cell survival and growth. J Dent Res 2004; 83: 104-108. 